\title{
Reflexiones sobre género, sexualidad y el Virus de Papiloma Humano
}

\author{
Considerations on Gender, Sexuality and Human Papillomavirus
}

\author{
GERARDO VALADEZ MÁRQUEZ* \& MARÍA LUNA LARA**
}

\begin{abstract}
Resumen: El siguiente ensayo pretende presentar al Virus de Papiloma Humano como un caso paradigmático que permite explorar algunas particularidades del género en su cruzamiento con la sexualidad. En primer lugar, se hace una revisión de literatura acerca de las particularidades de esta Infección de Transmisión Sexual y su importancia en el marco de la salud actual en México. Después se hace una breve genealogía del concepto de género, que pone énfasis en lo relacionado al sexo y la sexualidad, para después analizar los resultados de algunas investigaciones que resaltan la influencia del VPH en estos dos ámbitos. Por último, se hace una reflexión final sobre los elementos teóricos esbozados y cómo incorporarlos a posibles abordajes que permitan hacer recomendaciones preventivas en materia de salud sobre el VPH, teniendo en cuenta las particularidades de la infección y una perspectiva de género. Estas propuestas, abordarían las prácticas sexuales en relación a una cuestión del deseo y la identidad de género.
\end{abstract}

Palabras clave: VPH, infecciones de transmisión sexual, identidad de género, deseo.

\begin{abstract}
The essay pretends to present the HPV (Human papillomavirus) as a paradigmatic case in which some gender peculiarities crossed with sexuality. Firstly, there would be a literary revision about the particularities of this STIs (Sexually Transmitted Infections) and its importance in the public health domain in Mexico;

\footnotetext{
* Gerardo Macías Valadez Márquez: Docente Universidad Autónoma de San Luis Potosí, San Luis Potosí, México. Código ORCID: org/0000-0001-7554-7383 Contacto: mvmgerardo@ hotmail.com

** María Gabriela Luna Lara: Docente del Departamento de Psicología, División de Ciencias de la Salud, Campus León, Universidad de Guanajuato, Guanajuato, México. Código ORCID: org/00000002-4198-3950 Contacto: gabyluna@ugto.mx
} 
afterwards a brief genealogy of the concept of gender is done, which emphasizes the aspects of sex and sexuality, analyzing the results of some investigations that highlight the influence of HPV in these two spheres. Lastly, a final consideration is done about the theoretic elements shown is presented, and how make them part of possible approaches, that will allow preventive recommendations in matters of HPV health, considering the particularities of the infection and a gender perspective. These proposals will consider the sexual practices in relation to a matter of desire and gender identity.

Keywords: HPV, sexually transmitted infections, gender identity, desire.

\section{Introducción}

$\mathrm{L}$

airección General de Epidemiología (2014) realizó un estudio de 13 años, del 2000

al 2012, para conocer el comportamiento del VPH en México: encontró un aumento en la incidencia de casos (10.44 casos para el año 2000 y 34.31 para el 2012, por cada 100 mil habitantes) y un asenso del $26 \%$ en la prevalencia. Se atribuyó este aumento a la falta de información sexual y desconocimiento de la enfermedad.

Este desinformación puede ser a causa de los problemas para entender las cualidades de la infección y su dinámica, por ejemplo, Hilpert \& Brem (2013) describieron las dificultades de un grupo de participantes para transmitir a otros el conocimiento adquirido de internet sobre el VPH. A continuación, trataremos de describir a detalle sus características.

El Virus de Papiloma Humano (VPH) es un una enfermedad altamente transmisible, es la más frecuente en la mayoría de las poblaciones (Sanabria, 2009). Para Reiter, Pendergraft y Brewer (2010) la alta concordancia entre parejas con uno o más tipos de VPH, indica una alta transmisibilidad del virus, además su estudio habla de una alta susceptibilidad en mujeres a la infección (de los tipos 4-6, 17, 18, 54); esto debido a que la exposición al VPH en hombres "involucra al epitelio queratinizado del pene que es menos susceptible a la infección que la mucosa del cérvix" (p. 2960). La principal tasa de transmisión del VPH es mediante contacto sexual (60\%), después está el contagio por contacto piel con piel o autoinoculación, siendo el tipo 16 el que sobrevive en una superficie seca inanimada por más de siete días (Juárez-Albarrán y Juárez-Gámez, 2008).

Según Giuliano, Lazcano-Ponce, Villa, et al. (2008) en México, la mayor prevalencia de diagnóstico de VPH es en hombres entre los 25 y los 34 años, con una disminución hacía los jóvenes (menos de 20 años), lo que indica un mayor riesgo de adquisición del virus para este grupo.

La persistencia de VPH (responsable del 5.2\% de cánceres en el mundo: del canal anal, vagina, vulva, pene y oral) puede ser un factor etiológico para el desarrollo del 
cáncer cérvicouterino $(\mathrm{CaCu})$, que a nivel internacional es el segundo cáncer en frecuencia en mujeres (Zaldívar, 2012). En el año del 2008, el CaCu fue la principal causa de muerte de mujeres en México (INEGI, 2008).

La presencia del VPH no significa enfermedad, sino que es la Neoplasia Intraepitelial Cervical causado por el virus la que "implica tener una lesión visible al microscopio o colposcopio como resultado de la alteración de las células del epitelio" (Curiel-Valdés, 2008, p. 2). Es mejor conocida por sus siglas NIC y se suelen identificar dos fases, siendo la segunda la que determina presencia de cáncer. La persistencia del virus se genera a partir de trastornos inmunitarios locales cervicales y/o sistémicos (inducidos por el consumo de tabaco, presencia de SIDA, infecciones bacterianas [clamidia] o virales [herpes genital]. También la desnutrición (deficiencia de vitamina A, C, E y fosfatos) es un factor que contribuye a la persistencia (Zacarías-Flores, 2006).

Reiter, Pendergraft y Brewer (2010) en su estudio realizado con métodos de detección a nivel molecular, reporta que la duración de la infección por VPH en mujeres (para VPH no cancerígenos) fue de 4.3 a 11.1 meses y de 6.5 a 14.8 meses para VPH cancerígenos (tipos 4, 6, 17, y 18). En hombres la duración para ambos tipos (VPH cancerígenos y no cancerígenos) fue de 6 meses. Según la Secretaría de Salud del Estado de Veracruz (SSEV) (2014), la mayoría de las personas pueden eliminar el VPH mediante las defensas del organismo.

Existen dos vacunas que permiten crear anticuerpos contra la proteína L1 de la cápside del virus (capaces también de controlar la lesión, pero no de erradicar la persistencia del virus) (Curiel-Valdés, 2008). La efectividad de la vacuna (avalada por cinco años) es mayor en mujeres que no han iniciado una vida sexual. Actualmente en México existe un plan de vacunación a niñas de 9 a 12 años, cuya primera dosis fue aplicada en 2013 y la segunda fue aplicada en octubre de 2014. Se señala que la vacuna es una ayuda para prevenir cáncer cervical, pero no es un sustituto de los estudios de su detección (Papanicolau). (SSEV, 2014).

Así pues, a un plan de vacunación hay que considerar el seguimiento de tamizajes a mujeres que no reciban la protección inmunológica de la vacuna; además de la implementación de un programa de estrategias educativas a la población y personal de salud que permitan la aceptación de la vacuna y conceptos sociales sobre salud, prejuicios y representación del cuerpo (Torres-Poveda et al., 2011), el impacto en el comportamiento sexual de los adolescentes y conocimiento sobre el $\mathrm{CaCu}$ y el VPH.

Además de los relacionados con la salud física (como historia de neoplasia o la inmunosupresión) están: el número de compañeros sexuales y el número de parejas sexuales que éste haya tenido, así como el coito a temprana edad (antes de los 20 años). Los factores que disminuyen el riesgo de transmisión (además de la vacuna) y prevalencia son: el uso adecuado del condón, mantener relaciones sexuales con una pareja no infectada por el virus y evitar el contacto genital (Fournier, 2013; SSEV, 2014). Reiter, Pendergraft y Brewer (2010) reportan que la transmisibilidad del VPH en relaciones 
sexuales sin protección es en promedio del 40\%; en este estudio también se señaló como principal método de protección el uso del condón, así como la circuncisión.

La SSEV (2014) insiste en señalar que la infección del VPH "no es un indicador de práctica sexual insegura, ya que la transmisión no requiere la cópula, ni múltiples compañeros sexuales" (p. 20). El acento no debe estar puesto sólo en el acto coital, la sexualidad marcada por la amenaza de contraer éste o algún otro tipo de Infección de Transmisión Sexual sugiere considerar otras prácticas sexuales como el sexo oral, frotamiento y/o rozamiento de los genitales. Además de considerar estas otras prácticas, habría que pensar en qué es lo que facilita o no estos comportamientos sexuales de riesgo. En esta descripción del VPH y sus particularidades, podemos intuir una relación entre género y sexualidad, tal vez sea ahí donde podríamos encontrar alguna guía que permita identificar los factores que influyen en la transmisibilidad del VPH.

Con estos antecedentes, se expone a continuación una breve genealogía del concepto de género, poniendo énfasis en dos aspectos: la sexualidad y el sexo.

\section{La construcción del género: acerca del sexo y la sexualidad}

Para Laqueur (1990) el sexo como lo conocemos ahora fue inventado en el siglo XVIII, es decir, los órganos reproductivos pasaron a ser un lugar jerárquico de la diferencia, dos sexos bilógicos opuestos. Esta invención es explicada por medio del signo que se imbrica con sus similitudes, donde el hecho físico (el sexo), viene a poner en claro las cosas en un contexto político que concerniente al leguaje o lo científico. La realidad del sexo (una biología que entendía la diferencia como punto de partida), sustituyó la autoridad del género, que en la antigüedad era marcado desde lo social. Esto trajo consigo algunas discusiones como la relación entre placer sexual y la procreación, donde la atención se centraba en "la posibilidad biológica de una mujer sin pasión" (p. 276), por ejemplo, se afirmaba que la falta de placer sexual era causa importante de la infertilidad. El deseo sexual estaba atado a una cuestión biológica de procreación, con reservas de la existencia de relaciones no consentidas (una violación). Estas concepciones no cambiaron durante el siglo XIX, predominando "las casusas 'morales' de la infertilidad y otras repercusiones en el cuerpo de la desviación del 'buen orden' cubrían su camino en el mundo del sexo científico" (p. 328), lo que quiere decir, que en parte el rol del placer femenino residía en la cultura.

En el proceso de la comprensión del género, la masturbación como la prostitución tuvo su lugar importante. Para Laqueur (1990) hay que considerar estas dos actividades como perversiones sociales que se asientan en el cuerpo (y lo llevaban a su destrucción), más que como perversiones sexuales con efectos sociales. Para ambos sexos la masturbación fue considerada una enfermedad, y era definida como una "estimulación 
nerviosa excesiva y socialmente pervertida" (p. 386) asociada a la tuberculosis. Esta definición del vicio solitario apuntaba a la satisfacción de un deseo ilegítimo, contrario a considerarlo como "la desviación hacia sí mismo de un deseo sano" (p. 390). En el caso de la prostitución, esta era considerada una plaga social, donde el cuerpo y la sociedad se entrelazaban en esa batalla "contra el sexo no socializado" (p. 391). La masturbación y la prostitución condesaban el problema de si el sexo se debía practicarse como regla general en pareja, o si se podía hacerlo en solitario y/o con muchas personas.

Para Guinsber (2001) y Sohn (2006), la legalización de la píldora anticonceptiva en Estados Unidos en 1957 y luego en otros países, la vida de las mujeres cambió totalmente, pero les significó un acento en la vigilancia médica, además de que en ese momento "el ginecólogo no tiene equivalente masculino" (p. 113). En 1981 con la aparición del sida, "la sexualidad vuelve a convertirse en un problema de salud pública y mueve a los médicos a tratar de modificar las prácticas sexuales... asoció prevención, vigilancia de los «agentes de contaminación» y atención sanitaria” (p. 117). Estas preocupaciones inician una oleada de investigaciones "que se lanzan para identificar los comportamientos de riesgo [y] modifican el discurso sobre la sexualidad, que pasa de ser hedonista a ser sanitaria" (p. 117). Las propuestas principales para la prevención son el uso del preservativo y abstinencia. El siglo XX está marcado por un cuerpo sexuado (y su medicalización), haciendo florecer los discursos sobre los sexos y la sexualidad, olvidándose un poco de la historia de la liberación del deseo. En este periodo la escena pública combinó opiniones entre prácticas sexuales y un discurso sobre la sexualidad. Será pues el pudor lo que esté detrás de las discusiones del cuerpo sexuado, enmarcadas por las exigencias y libertades que se le plantean.

En la segunda parte de su historia sobre la sexualidad, Foucault (1991) intenta mostrar que existe "una tensión creciente entre placer y la salud... la idea de que el sexo tiene sus peligros es mucho más fuerte en el siglo II de nuestra era que en los siglos IV y V antes de J.C.” (p. 190). En esos siglos antes de Cristo, no se condena las perversiones, el sexo se convierte en un asunto de exceso (hybris) o moderación, "para ello era preciso convertirse completamente en maestro de uno mismo" (192). También explica, que los tomos de su historia de la sexualidad son "una historia de la moral... [y] cuando se trata de la historia de la moral hay que distinguir entre los actos y el código moral" (p. 195). La moral es entendida por Foucault (2013) como "un conjunto de valores y reglas de acción que se proponen a los individuos y los grupos por intermedio de diversos aparatos prescriptivos, como pueden serlo la familia, las instituciones educativas, las iglesias, etc." (p. 179). En un primer momento, Foucault (1991) consideró al sexo como un dato ocultado por el discurso de la sexualidad; después meditó la posibilidad de que el sexo fuera producto del dispositivo de sexualidad, hasta que llegó a afirmar que "se tiene una sexualidad desde el siglo XVIII, un sexo desde el siglo XIX. Antes, sin duda se tenía una carne" (p. 145). 
Sohn (2006) resume de la siguiente manera los aspectos más significativos en el ámbito de la sexualidad durante el siglo XX:

1) Por una parte, con el derecho al placer también se presentó "el rechazo de la violencia sexual y de una sexualidad obligada" (p. 118). El consentimiento informado que acompaña a la libertad sexual significa un rechazo a la violencia sexual; "la inviolabilidad del cuerpo constituye así la nueva barrera del deseo" (132) y las expresiones de la sexualidad ya no se juzgan sólo bajo la moral, ahora "se valoran en función del placer, el dolor y el asco físico" (p. 119).

2) La precisión en el lenguaje anatómico permitió una distancia entre órganos y gestos, "esta evolución lingüística saca a la sexualidad de la clandestinidad y favorece audacias crecientes en el dormitorio" (p. 118).

3) Se dio también la disociación definitiva entre sexualidad y reproducción, así "el deseo de no tener ese hijo es más fuerte que el miedo al sufrimiento o la enfermedad" (p. 122), este aspecto está marcado por el uso de la píldora anticonceptiva. Entre los motivos para la contracepción era el deseo de proporcionar una buena educación y tener estabilidad económica, por lo que se orientaba al control natal. Cabe señalar que, en el siglo XVIII, las prácticas de contracepción procuraban la salud de los recién nacidos, en la opinión Foucault (1991) "la contracepción inducida por una política natalista, ¡es muy gracioso! [...] la tradición médica y popular quería en efecto que una mujer cuando estuviera criando, no tuviera ya derecho a tener relaciones sexuales, de otro modo la leche se echaría a perder" (p. 161).

4) También se posibilitó "una sexualidad que ya no se limita al campo estrechamente controlado del matrimonio" (p. 123), esto debido a que "a partir de la década de 1960, el amor lo disculpa todo, aunque no exista un proyecto matrimonial" (p. 124), empero, en las relaciones "la amenaza de un embarazo sigue siendo una espada que pende sobre la vida amorosa" (p. 122), y en las relaciones más duraderas "las chicas deben enfrentarse con una nueva táctica: el chantaje de la ruptura” (p. 133), llegando a ceder frente al miedo de ser abandonadas. Se va zanjando una distancia entre sexualidad y matrimonio, donde no se trata sólo de defender las experiencias prematrimoniales bajo la premisa del entendimiento conyugal, "sino que reivindican también el derecho a satisfacer, sin remordimientos y al margen de los afectos, los deseos y pulsiones sexuales" (p. 125). Se menciona también que el aprendizaje sexual de esa época se dio principalmente por un conocido y pocas veces mediante la prostitución.

El vouyerismo y los cambios de pareja serán los últimos tabúes del siglo $\mathrm{XX}$, donde "las mujeres suelen negarse a contraer una nueva unión después de quedarse viudas y tienen tendencia a poner punto final a su vida sexual" (Sohn, 2006: 126). 
Para Dorlin (2009) el modelo bicategorial del sexo es "un 'obstáculo epistemológico' para la comprensión científica del 'sexo', como un proceso complejo de sexuación, irreducible a dos categorías de sexo" (p. 38), y dice que el concepto de género “no fue 'inventado' por el saber feminista, fue elaborado por los equipos médicos que, en el curso de la primera mitad del siglo XX, se hicieron cargo de los recién nacidos llamados 'hermafroditas' o intersexos" (31). Esta perspectiva reafirma el argumento de la importancia que tuvo la referencia al cuerpo como signo de la diferencia, el cual marcó una pauta importante para hablar de género, y en el cual se depositaban las referencias sociales y culturales, ahora queda claro que "el sexo biológico no determina la identidad sexual de los individuos (de género y de sexualidad)" (p. 33). Tampoco habría que privilegiar la distinción entre sexo y género, ya que se corre el riesgo de naturalizar lo social y descuidar "la distinción entre `sexuación' y 'sexo', entre un proceso biológico y su reducción categorial a los sexos ‘macho', 'hembra'” (p. 36). Con la distinción entre sexo y el género, que rompe la relación entre cuerpos sexuados y lo biológico, se van aclarando también las desigualdades sociales entre hombres y mujeres. La capacidad normativa del género que interviene en el proceso de sexuación de dos sexos biológicos logra su propósito porque mantiene un régimen teórico y práctico en crisis, es decir, que aunque se desprecie en la práctica una normativa natural polimorfa, que los presupuestos teóricos estén en conflicto, permite por ejemplo, un discurso sobre "la heterosexualidad reproductiva, que define lo femenino y lo masculino por la polarización sexual socialmente organizada de los cuerpos" (p. 49). Con esto se quiere decir que "el concepto de género es a su vez determinado por la sexualidad, comprendida como un sistema político" (p. 49). El autor concluye que "si el género precede al sexo, debemos admitir que la sexualidad precede al género" (p. 49).

La propuesta de Foucault (1991) también indica que en el fondo de todo el tramado sobre género y el sexo, está la sexualidad, y nos dice que como objeto de estudio "es en realidad un instrumento formado hace ya mucho tiempo, que ha constituido un instrumento de servidumbre milenario" (p. 153). Es el dispositivo de la sexualidad el método de análisis que le permite mirar con claridad detrás de todo ese ocultamiento. Como dispositivo, se entiende aquello que "permite separar, no lo verdadero de lo falso, sino lo inclasificable científicamente de lo clasificable" (p. 131). Foucault (2013) menciona que el término sexualidad "apareció tardíamente, a comienzos del siglo XIX" (p. 159), y que él entiende la sexualidad como experiencia, "si se entiende por experiencia la correlación, en una cultura, entre dominios de saber, tipos de normatividad y formas de subjetividad" (p. 160). Es pues importante pensar el género desde la sexualidad y sus avatares, como las ITS. Un caso paradigmático de estas ha sido el SIDA.

En 1960, nos dice Moulin (2006), aparece el SIDA “como una enfermedad de transmisión sexual, [que] iba contracorriente de la liberación de las costumbres a la década" (p. 40), esta enfermedad de transmisión sexual "como en las epidemias de tiempos remotos, algunos lo interpretaban como una venganza divina, resucitando la intolerancia, o incluso la búsqueda de chivos ex-piatorios" (p. 40). Sontag (2005) nos dice 
que el SIDA ha sido considerado un castigo por la inmoral de quienes la padecían. También supuso que el cáncer es una enfermedad a la que son especialmente propensos, los derrotados psíquicos, los inexpresivos, los reprimidos - sobre todo los que han reprimido la ira o el sexo- - tal como durante todo el siglo XIX y parte del XX (de hecho, hasta que se encontró la manera de curarla) se consideraba la tuberculosis como una enfermedad típica de los hipersensibles, los talentosos, los apasionados. Sontag (2005) escribe sobre el SIDA desde la experiencia de haberla padecido, describe que la reputación y las ficciones de esa enfermedad la distrajeron de vivir su propio terror, acentúa la fuerte resonancia que pueden tener las metáforas del SIDA, entre ellas las "metáforas militares" (103): un agente infeccioso que ataca desde el exterior.

Butler (2011) dice que la definición de una enfermedad, como es el caso de la diferencia entre VIH positivo y SIDA, pueden ser "discriminaciones discursivas muy importantes que tienen implicaciones cruciales, pues describen la realidad y, al hacerlo, producen también esta realidad social" (p. 70). Al hablar de VPH, hay que pensar que también estamos describiendo una realidad, en este caso, la experiencia de la sexualidad y la de género.

Butler (2007) describe que el género ha sido abordado desde varias perspectivas, éstas están en relación con los significados que pueda producir:

1) El género (desde una posición feminista humanista) como un atributo que denomina una persona, "que a través de un gesto misógino de sinécdoque ha ocupado el lugar de la persona, el cogito autodeterminante... dicho de otra forma, solo los hombres son «personas» y solo hay un género: el femenino" (p. 76).

2) La anterior postura fue sustituida por la concepción (histórica y antropológica) del género como una relación o conjunto de relaciones en contextos concretos que existen en oposición a otro significado, es decir, lo masculino frente a lo femenino y sus diferentes manifestaciones histórico-culturales.

3) el sexo femenino como ausencia u opacidad lingüística, que hace referencia a un sexo que no puede pensarse, sin embargo, "dentro del discurso legado por la metafísica de la sustancia, el género resulta ser performativo, es decir, que conforma la identidad que se supone que es. En este sentido, el género siempre es un hacer, aunque no un hacer por parte de un sujeto que se pueda considerar preexistente a la acción” (p. 84).

Ahora bien, el género como experiencia que unifica sexo, género y deseo tiene dos posibilidades:

- “Cuando el género es una designación psíquica o cultural del yo -y el deseo- [y]

- cuando el deseo es heterosexual y, por lo tanto, se distingue mediante una relación de oposición respecto del otro género al que desea" (Butler, 2007: 80). 
La investigación de Vargas (2003) habla de este aspecto donde el género "es lo propio del otro sexo" (p. 147). Llega a la conclusión de que cada género produce al otro, es decir, "cada subjetividad femenina produce la masculinidad de los hombres y cada subjetividad masculina produce la feminidad de las mujeres" (p. 143). Su propuesta invita a pensar que las cualidades del género dependen de lo que el otro conceda, ya sea como su opuesto o como su diferencia, así pues "cada sujeto se asume como el que es y como el que no es, y el otro del género constituye los límites de lo que cada uno es y no es... [y] el cambio del otro pone en riesgo lo que cada uno es" (p. 145-146).

En la concepción de Butler (2007) sobre el género, explica “que el deseo refleja o expresa al género y que el género refleja o expresa al deseo" (p. 80), así lo masculino se distinguiría de lo femenino mediante las prácticas del deseo heterosexual. Para Butler (2002) la identificación no se puede verificar, pues "la identificación es la escenificación fantasmática del evento" (p. 159), que se convierte en "esfuerzos fantasmáticos de alineamiento, de lealtad, de cohabitación ambigua y transcorporal; desestabilizan el 'yo'; son la sedimentación del 'nosotros'" (p. 159). Esta identificación, entendida como una iterabilidad performativa (ya que "lo performativo funciona para producir lo que declara" (p. 163) tiene su base en la prohibición. Así pues "el 'sexo' siempre se produce como una reiteración de normas hegemónicas” (p. 162), pues para que sean eficaces, los actos performativos deben repetirse. También está el género como estilo corporal que tienen tres dimensiones:

1) “el sexo anatómico,

2) la identidad de género $y$

3) la actuación de género" (Butler, 2007, p. 268)

Para Butler (2007) es importante "la redescripción de los procedimientos intrapsíquicos, desde el punto de vista de la política de superficie del cuerpo" (p. 265), entendiendo que el yo es un ser corpóreo y el cuerpo el lugar donde se origina el placer y el deseo. Szasz (2002) reporta en sus investigación con mujeres rurales que practicaron la anticoncepción quirúrgica, que la sexualidad tienen normas que corresponden a la construcción cultural del género (sexualidad vinculada a la procreación; lo que niega la posibilidad de sentir deseo y placer en relaciones sexuales no procreativas), por lo que entre mayor arraigada la identidad de género, mayor es el control sobre la sexualidad.

\section{La interferencia del Virus de Papiloma Humano en la sexualidad}

Castellsagué, Bosch y Muñoz (2003) pretenden explicar la transmisibilidad del VPH, donde el riesgo en la mujer "depende menos de su comportamiento sexual que del de su esposo u otro hombre" (p. 346). Se describen distintos patrones de comportamiento sexual 
en las sociedades, los cuales pretende acentuar el rol del hombre en la transmisibilidad del VPH:

Patrón A: Hombre y mujeres son monógamos.

Patrón B: Mujeres monógamas y hombres con varias parejas sexuales

Patrón C: Hombres y mujeres tienden a tener varias parejas sexuales.

Así pues, en el patrón A, la transmisibilidad es menor que en los patrones B y C. Según esta explicación el comportamiento sexual de hombres, en específico el contacto con prostitutas, puede ser un factor importante en el contagio de VPH.

Para Maissi, Marteau, Hankins, et al. (2004) el diagnóstico de VPH en mujeres está asociado a un alto nivel de ansiedad, angustia y preocupación; tres fueron las variables involucradas en predecir la ansiedad: la edad (las de menor edad reportaron más ansiedad), percepción de riesgo de desarrollar cáncer cervical (el cual fue mayor en mujeres diagnosticadas que en otros grupos), y no saber qué significa los resultados del test (22\% [217/1003] de mujeres no supieron qué significaban sus resultados y estuvieron asociadas a altos niveles de ansiedad). Las dos variables también predicen la angustia y la preocupación. Sanabria (2009) dice que en la detección tanto del VPH "como de lesiones cervicales produce un estado de ansiedad y depresión" (p. 57), este estado de ánimo parece estar relacionado a la percepción de riesgo para la salud, es decir, la posible presencia de cáncer, dificultades futuras durante el embarazo, etc.

En el estudio de Teixeir, Fraxe, Alves y Sousa (2005), las entrevistas a mujeres sobre el VPH indicaron que todas tienen conciencia de la gravedad y de la forma de transmisión del virus y reconocen al condón como la mejor estrategia de prevención, aunque lo perciben como un elemento incómodo en la sexualidad de la pareja, además de no sentirse cómodas al sugerir su uso, por ser este algo que compete al hombre. El no uso del preservativo estuvo asociado a: falta de información, disminución de la autoestima, desatención en el autocuidado, falta de autonomía, vergüenza o miedo a exponerse a una situación embarazosa por el uso del preservativo. Para estas mujeres tener VPH interfiere en las relaciones porque "produce un conflicto advenido a la cuestión 'quién ha contagiado a quién'” (p. 194). Así, su preocupación estuvo en sentirse traicionadas por sus parejas, porque supone les han sido infieles "una mujer que siempre ha desconfiado de la fidelidad de su marido, puede ver su sospecha confirmada" (p. 193); en otros casos, la mujer pudo ver al VPH como un castigo por haber sido infiel.

También Sanabria (2009) dice que independientemente de diagnóstico citológico, algunas mujeres diagnosticadas positivo al VPH, reportaron peores relaciones sexuales, además "se sentían peor acerca de sus relaciones pasadas y futuras comparadas" (p. 57). Esto puede ser debido a que el ejercicio de la sexualidad se ve cuestionada. Gálvez y Castro (2013) dicen que el VPH y el CaCu están estigmatizados por la relación directa al número de parejas sexuales: este estigma es autoimpuesto (o interno), y provoca que 
algunas mujeres se aíslen y vivan en silencio el proceso de salud/enfermedad/atención para no dañar sus relaciones significativas. Otra consecuencia del contagio de VPH es la disminución de la actividad sexual. También señalan que el descubrimiento de alguna ITS puede provocar disfunciones sexuales y la separación de relaciones de pareja; este último por la desconfianza provocada por la convivencia de tener un compañero infectado.

\section{El Virus de Papiloma Humano y el género: sobre las relaciones sexuales, de pareja y el uso del condón}

En las entrevistas focalizadas realizadas por Quinto (2012) a mujeres y hombres de entre 20 y 25 años, señalan que es en la escuela y el ámbito familiar donde los jóvenes obtienen principalmente información sobre sexualidad, métodos anticonceptivos y prevención de ITS. En el ámbito familiar se hace énfasis en evitar el embarazo y de manera secundaria la protección contra ITS. Pero es en los procesos de socialización con iguales donde se conforma el significado que se da "a temas relacionados con los vínculos de pareja, el ejercicio sexual femenino y masculino, el embarazo y las infecciones de transmisión sexual" (p. 179). Los tipos de relaciones de las que hablaron los sujetos, que "expresaron una valoración positiva a la experimentación sexual en el contexto de diversas formas relacionales que no convergen con la idea de un matrimonio o un embarazo cercano" (p. 180), se clasificaron en: noviazgo, relaciones de amantes y vínculos ocasionales. La fidelidad monógamica caracteriza al primer tipo, en las segundas no se expresa algún compromiso explícito, pero hay un interés por la convivencia, y en los vínculos ocasionales, el compromiso es limitado y "no rebasa la pura satisfacción en la arena sexual" (p. 183). La importancia de las relaciones de pareja es que permiten la identificación del ser hombre o mujer, y la conexión entre sexualidad femenina y masculina; así en el proceso de los rituales de cortejo se ejecutan roles y se hace referencia a códigos de cómo debería ser tratado por el otro. Estos tres tipos de relaciones (noviazgo, relaciones de amantes y vínculos ocasionales) tienen diferente comportamiento respecto del uso del condón: en el noviazgo se abandona su uso bajo la premisa de la fidelidad monógamica, este compromiso de exclusividad sexual tiende a disminuir la percepción de riesgo de adquirir una ITS (se señala que es el código de confianza el que contribuye a este disminución, junto con el de amor-pasión); en los otros dos tipos se incrementa el uso del preservativo. Otro elemento que contribuye a prácticas no seguras es la esperanza de que la relación de amantes u ocasional transite a un vínculo formal, "el no uso del condón puede ser un símbolo que comunica la disposición para entablar un compromiso de fidelidad monogámica y la confianza para entablar otro tipo de relación más formal" (p. 186-187). La estabilidad de una relación y el desarrollo de confianza contribuyen a la disminución del uso de protección, así pues, según esta conclusión, el riesgo sería para las personas que se orientan a tener relaciones sexuales en un contexto romántico de pareja monógamica bajo un esquema de confianza. 
Para Pedraza (2013) la baja utilización de condón, el mayor número de compañeros sexuales y la percepción de que su pareja ha tenido parejas concurrentes incrementa las posibilidades de tener una displasia; siendo el número de parejas sexuales el elemento más importante (el intervalo de tiempo entre parejas parece ser un factor importante). En las trayectorias sexuales presentadas en su estudio "la presencia de displasias/VPH se asoció al comportamiento de su compañero sexual" (p. 192), también la percepción de la mujer de "que la última pareja le era infiel incrementó la probabilidad de tener displasia" (p. 193). Las mujeres sin displasia presentaron mejor percepción de riesgo de ITS y son buenas usuarias de métodos de protección. Es importante señalar que las mujeres que reportaron uso del condón en la primera relación sexual disminuyeron la probabilidad de tener displasia.

El análisis discursivo de Gayet (2011) en archivos históricos y a jóvenes universitarios entrevistados, muestra que hay tres líneas argumentales sobre el riesgo de contraer una ITS:

1) El esquema primario: este se caracteriza por la feminización de las ITS, es decir, se focaliza las infecciones en las prostitutas y las "mujeres fáciles".

2) Los otros grupos de riesgo: el autor llama a esto, argumentos en los intersticios, y pone el acento en la identificación de grupos de riesgo y vulnerables, se señala como fuente de contagio a "los extranjeros, las niñas bien, los faltos de higiene, los obreros, la población rural, los homosexuales, la población de sitios fronterizos y turísticos" (p. 272), mientras no se tenga relación con estos grupos, no habría riesgo de contraer ITS.

3) El enfoque en las prácticas: surge en la última década del siglo XX y viene a sustituir la etapa anterior que orienta a la discriminación. En esta se señalan las prácticas que pueden conducir a un riesgo de infección, como el coito sin condón.

Estas tres líneas argumentales son un producto histórico y cultural, y "no son inalterables, se construyen y reconstruyen permanentemente a partir de múltiples disputas ideológicas y prácticas" (Gayet, 2011, p. 273), por lo que supone no su desaparición sino su actualización constante y complementariedad.

Específicamente en el análisis del discurso de los jóvenes hecho por Gayet (2011) en referencia a los riesgos sexuales, se sugiere "que la mujer se embaraza y el hombre se infecta" (p. 275). En la jerarquización de estos, el embarazo está en primer lugar seguido por la adquisición de SIDA, “aunque señalaron que este último sólo está presente en el nivel discursivo y no en sus prácticas sexuales" (p. 275), también se comentó que las ITS no estaban presentes en su entorno y que hablar de ellas no es fácil debido a los estereotipos que las rodean. En este sentido se encontraron dos sesgos en la percepción de riesgo: "el de inmunidad ("no me va a pasar a mí") y el de complacencia ("fuera de la vista, fuera de la mente")" (p. 275). En sus patrones de interacción se identificó una tipificación según el esquema primario, describiendo a las mujeres como 'buenas' y 
'zorras', asumiendo que el riesgo está en el contacto con las segundas. Esa misma tipificación se usó en la lógica del uso del condón, "lo usan con las novias para prevenir embarazos, y con las 'locas' o las trabajadoras sexuales, para prevenir ITS” (p. 276-277). Se afirmó que portar permanentemente un condón puede ser la clave para tener prácticas protegidas, pero esta situación puede ser condicionada por los estereotipos que modela la interacción sexual, "la mujer que porta condones puede ser calificada de 'zorra', el hombre que los porta puede ofender a la mujer por ser considerado una manifestación de deseo sexual" (Gayet, 2011, p. 277). Por último, se explica que la búsqueda de culpables cuando se contrae una ITS reproduce el sistema de género tradicional. Habría en su lugar que reconocer la importancia del deseo y el placer sexual, para alejarse de los estereotipos y grupos estigmatizados a la hora de la prevención de ITS.

\section{Reflexiones finales}

Se mencionaron algunas perspectivas sobre la construcción el género enfatizando, por un lado, el sexo como fundamento, cuya referencia a lo genital acentúa lo tangible y lo fisiológico, y por otro, la sexualidad que permite explorar las particularidades subjetivas e individuales, como el ejercicio sexual y el deseo. La relación entre estos tres conceptos (sexo, género, sexualidad) parece estar estrechamente relacionada, pero su trasposición a veces no es tan clara. Encontramos al género como una construcción previa al sexo, luego al género marcado por el sexo enfatizado por la medicina y la organización genital, después a la sexualidad como producto de la teorización de estas dos posiciones anteriores (sobre lo que significa ser hombre o mujer), y por último, la construcción de género que se cruza con la sexualidad y sus prácticas.

El VPH es expuesto como un caso que permite analizar el cruzamiento entre género y sexualidad de manera importante. Por un lado, cabría preguntar desde una perspectiva de género qué es lo que facilita ciertas prácticas sexuales de riesgo para la adquisición de VPH, es decir, si la performatividad del género (entendida desde la identidad y actuación de género) está relacionada con prácticas sexuales de riesgo. En este aspecto habría que profundizar sobre su iterabilidad performativa, tanto a nivel de lenguaje como de su actuación. Siguiendo este planteamiento, se podría identificar aquellos actos performativos del habla (Butler, 2002), que nos den indicios de esas demandas (mandatos, prohibiciones, etc.) que el género impone a la sexualidad de cada sujeto.

También sería importante conocer si el diagnóstico de VPH produce un cambio o no en las prácticas sexuales de las personas afectadas, para así pensar en el ejercicio de la sexualidad y los efectos de la dimensión social del propio padecimiento, para que además de comprender los determinantes de la identidad de género, se considere el papel del 
deseo, entendido este como actuación de género. Profundizar en estas cuestiones podría orientar a mejorar las recomendaciones preventivas en materia de salud sobre el VPH. 


\section{Referencias}

Agenda San Luis. (2014). Aplicarán vacuna contra el Virus de Papiloma Humano a niñas de 9 a 11 años. San Luis: Agenda San Luis. http://www.agendasanluis.com/eventos/aplicaran-vacuna-contra-el-virus-delpapiloma-humano-ninas-de-09-11-anos/

Butler, J. (2002). Cuerpos que importan: sobre los límites materiales y discursivos del "sexo". Buenos Aires: Paidós.

Butler, J. (2007). El género en disputa. El feminismo y la subversión de la identidad. Buenos Aires: Paidós.

Butler, J. (2011). Violencia de Estado, guerra, resistencia. Por una política de la izquierda. Buenos Aires: Katz.

Castellsagué, X. Bosch, F. X. y Muñoz, N. (2003). The male role in cervical cancer. Ciudad de México: Salud Pública de México, 45(3), 345-353.

Curiel-Valdés, J. de J. (2008). El diagnóstico del virus del papiloma humano en el contexto de la vacuna. Ciudad de México: Cirugía y Cirujanos, 76(1), 1-3.

Dirección General de Epidemiología (DGE) (2014). Desarrollo, evolución y estadística del Virus de Papiloma Humano. Madrid: Boletín Epidemiológico, 16(31), 1-68. http://www.epidemiologia.salud.gob.mx/doctos/boletin/2014/completo/sem16.p df

Dorlin, E. (2009). Sexo, género y sexualidades. Introducción a la teoría feminista. Buenos Aires: Nueva Visión.

Foucault, M. (1991). Saber y verdad. Barcelona: La Piqueta.

Foucault, M. (2013). La inquietud por la verdad. Escritos sobre la sexualidad y el sujeto. Madrid: Siglo XXI.

Gálvez, A. M. del C. y Castro, V. M. del C. (2013). El estigma en mujeres diagnosticadas con VPH, displasia y cáncer cervicouterino en Hermosillo, Sonora. Bogotá: Estudios Sociales, 23(42), 259-278.

Gayet, C. I. (2011). Infecciones de transmisión sexual en México: la influencia de las relaciones de género en la construcción del riesgo (Tesis doctoral). Ciudad de México: COLMEX.

Giuliano, A. R., Lazcano-Ponce, E., Villa, L. L., et al. (2008). The Human Papillomavirus 
Infection in Men Study: Human Papillomavirus Prevalence and Type Distribution among Men Residing in Brazil, Mexico, and the United States. Philadelphia: Cáncer Epidemiol Biomarkers Prevention 17, 2036-2043.

Guinsber, E. B. (2001). Fantasías (tal vez delirantes) acerca de lo que hoy diría Freud sobre la sexualidad. En: I. M. Jáidar (Comp.). Ciudad de México: Sexualidad: símbolos, imágenes y discursos.

Hilpert, C. J. y Brem, K. S. (2013). Dissatisfaction and engagement as motivators of conceptual change in a naturalistic internet-based search about HPV. Almería: Electronic Journal of Research in Educational Psychology, 11(30), 285-310.

Instituto Nacional de Estadística y Geografía (INEGI). (2008). Mujeres y hombres en México 2008. Archivo 2. Ciudad de México. http://www.inegi.org.mx/prod_serv/contenidos/espanol/bvinegi/productos/integr acion/sociodemografico/mujeresyhombres/2008/myh2008feb28_2.pdf

Juárez-Albarrán, A. C. y Juárez-Gámez, C. A. (2008). Vacuna contra el virus del papiloma humano. Ciudad de México: Revista Medica Instituto Mexicano del Seguro Social, 46(6), 631-638.

Laqueur, T. (1990). La construcción del sexo. Cuerpo y género desde los griegos hasta Freud. Madrid: Editorial Cátedra.

Maissi, E., Marteau, T. M., Hankins, M., Moss, S., Legood, R. y Gray, A. (2004). Psychological impact of human papillomavirus testing in women with borderline or mildly dyskaryotic cervical smear test results: cross sectional questionnaire study. Londres: The BMJ, 328, 1293-1296.

Moulin, A. M. (2006). El cuerpo frente a la medicina. En: J.-J. Courtine (Dir.), Historia del cuerpo. Las mutaciones de la mirada en el siglo XX. Madrid: Taurus, 3, 2980 .

Pedraza, N. C. (2013). Trayectorias sexuales y riesgo de ITS/VPH en mujeres adultas de la delegación Venustiano Carranza en la Ciudad de México (Tesis doctoral). Ciudad de México: COLMEX.

Quinto, F. E. P. (2012). Sexualidad y género: un estudio sobre relaciones de pareja y prácticas sexuales de uso y no uso del condón en jóvenes mexicanos (Tesis de maestría). Ciudad de México: COLMEX.

Reiter, P. L., Pendergraft, W. F. y Brewer, N. T. (2010). Meta-analysis of Human Papillomavirus Infection concordance. Philadelphia: Cancer Epidemil Biomakers Prev, 19, 2916-2931. DOI: 10.1158/1055-9965.EPI-10-05 
Ríos, S. M. R. y Mendoza, A. F. (2012). Programa de prevención de riesgo de cáncer cervicouterino $(\mathrm{CaCu})$ para estudiantes universitarias. Ciudad de México: Alternativas en Psicología, 16(26), 68-77.

Sanabria, J.G. N. (2009). Virus del Papiloma humano. Santiago: Revista Ciencias Médicas, 13(4), 1-23.

Secretaría de Salud del Estado de Veracruz (SSEV). (2014). Semanas Nacionales de Salud. Veracruz. http://web.ssaver.gob.mx/saludpublica/files/2014/02/mensajeroSNSalud.pdf

Sontag, S. (2005). La enfermedad y sus metáforas y El SIDA y sus metáforas. Madrid: Taurus.

Sohn, A.-M. (2006). El cuerpo sexuado. En: J.-J. Courtine (Dir.). Historia del cuerpo. Las mutaciones de la mirada en el siglo XX. Madrid: Taurus.

Szasz, I. (2002). Género y valores sexuales. Un estudio de caso entre un grupo de mujeres mexicanas. En: F. J. Mercado, D. Gastaldo \& C. Calderón. Investigación cualitativa en salud en Iberoamérica. Guadalajara: Métodos, análisis y ética, Universidad de Guadalajara, Centro Universitario de Ciencias de la Salud.

Teixeir, D. Q., Fraxe, S. P., Alves, R. de S. (2005). Infecção pelo Papiloma Vírus Humano (HPV): incertezas e desafíos. São Paulo: Acta Paulista de Enfermagem, 18(2), 190-196. http://www.redalyc.org/src/inicio/ArtPdfRed.jsp?iCve=307023799012

Torres-Poveda, K. J.; Cuadra-Hernández, S. M.; Castro-Romero, J. I. y Madrid-Marina, V. (2011). La política focalizada en el programa de vacunación contra el Virus del Papiloma Humano en México : aspectos éticos. Santiago: Acta Bioethica, 17(1), 85-94. DOI: 10.4067/S1726-569X2011000100010

Vargas, I. L. E. (2003). El otro género. En: I. M. Jáidar (Comp.) (2003). Convergencias en el campo de la subjetividad. UAM-X, CSH, Depto. de Educación y Comunicación.

Zacarías-Flores, M. (2006). Virus del papiloma humano (VPH) y su potencial prevención a través de una vacuna. Ciudad de México: Bioquimia, 31 (3), 83-84.

Zaldívar, G. L. de L., Martin, F. M., et al. (2012). Cáncer cérvicouterino y virus del papiloma humano. Santiago: Revista Chilena Obstétrico-Ginecológica, 77 (4), 315-321. DOI: 10.4067/S0717-75262012000400014 